\title{
The Effect of Education Based on Theory of Planned Behavior on Physical Activity of High School
}

\begin{abstract}
Background and Objective: Regular physical activity is one of the components of a healthy lifestyle that improves public health, reduces burden of disease and medical costs in societies. Mashhad high school girl students were recruited.

Materials and Methods: This quasi-experimental study was performed on 68 high school girl students in Mashhad. After determining the needs, educational intervention was conducted within the framework of the theory of planned behavior in the respective schools. Data were collected in three stages before and immediately after three months of educational intervention by Planned Behavioral Questionnaire and International Physical Activity Questionnaire (IPAQ) by SPSS 16 software. Mann-Whitney, regression and duplicate data analyzes were used in data analysis. Results: The findings showed that there was a significant difference in the mean scores of planned behavior theory structures in the experimental group compared to the control group after the educational intervention. Also, the level of physical activity of the girls increased after the intervention compared to before the intervention. However, these changes were not significant due to research limitation $(p<0.05)$ Conclusion: the implementation of educational program based on the theory of planned behavior through increasing attitudes, subjective norms and behavioral intention along with creating the necessary infrastructure to create behavior can have a positive impact on promoting adolescent girls' tendency. To have physical activity Keywords: Behavior, Physical Activity, Health Education, Student Paper Type: Research Article.
\end{abstract}

Citation (Vancouver): Asa-kohnefroody Z, Peyman N, Ghodsikhah F, ShakeriNejad Gh. The Effect of Education Based on Theory of Planned Behavior on Physical Activity of High School . Iran J Health Educ Health Promot. Spring 2020;8(3):210 -223. [Persian]x

> Citation (APA): Asa-kohnefroody Z, Peyman N, Ghodsikhah F, Shakeri-Nejad Gh. The Effect of Education Based on Theory of Planned Behavior on Physical Activity of High School . Iranian Journal of Health Education \& Health Promotion., 8(3), 210-223 . [Persian]
Zahra Asa-kohnefroody

Social Determinants of Health Research Center, Mashhad University of Medical Sciences, Mashhad, Iran

MSc in Health Education and Health Promotion, School of Health, Mashhad University of Medical Sciences, Mashhad, Iran

Nooshin Peyman

Social Determinants of Health Research Center, Mashhad University of Medica Sciences, Mashhad, Iran

* Professor, Department of Health Education and Health Promotion Faculty of Health, Mashhad University of Medical Sciences, Mashhad, Iran. (Corresponding Author):

peymann@mums.ac.ir

Fatemeh Ghodsikhah

Social Determinants of Health Research Center, Mashhad University of Medica Sciences, Mashhad, Iran

Department of Epidemiology and Biostatistics, School of Public Health, Mashhad University of Medical Sciences, Mashhad, Iran

Ghoratollah Shakeri-Nejad Social Determinants of Health Research Center, Mashhad University of Medical Sciences, Mashhad, Iran

Social Health Factors Research Center, Ahvaz University of Medical Sciences, Ahwaz, Iran

Received: 2019/09/07

Accepted: 2020/03/17

Doi: 10.29252/ijhehp.8.3.210 


\section{تاثير آموزش مبتنى بر نظريه رفتار برنامه ريزى شده بر فعاليت جسمانى دختران دبيرستانى}

$$
\text { زهرا آساكهنه فرودى }
$$

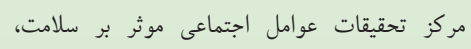

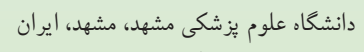

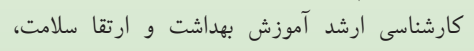

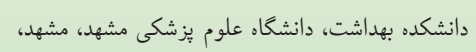

مركز تحقيقات عوامل اجتماعى موثر بر سلامت، بران

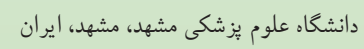

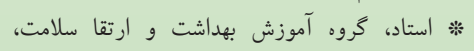

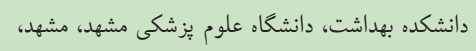
peymann@mums.ac.ir

$$
\text { ايران. (نو يسنده مسئول): }
$$

$$
\text { فاطمه قدسى خواه }
$$

مركز تحقيقات عوامل اجتماعى موثر بر بر باه

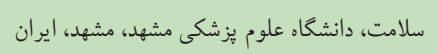

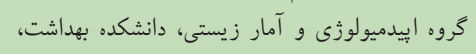

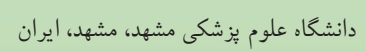
قدرت الله شاكرى نزاد مركز تحقيقات عوامل اجتماعى موثر بر براد سلامت،

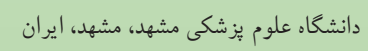

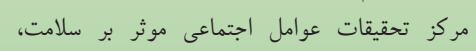

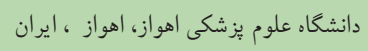

تاريخ د ريافت: 9 |

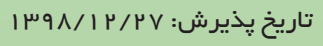

\section{حكيل}

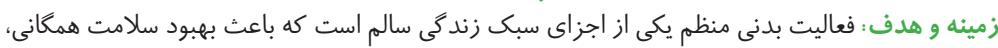

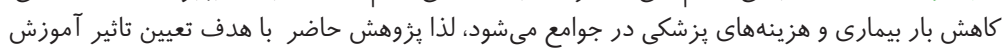

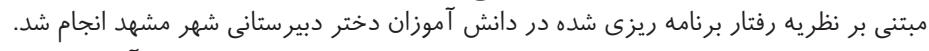

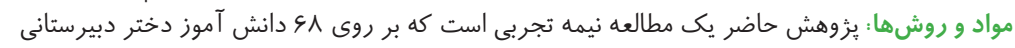

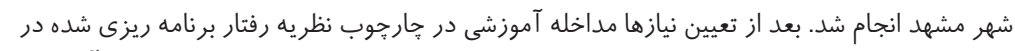

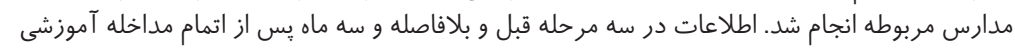

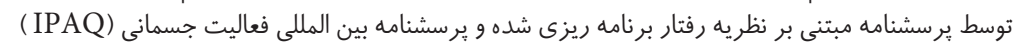

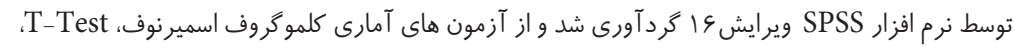

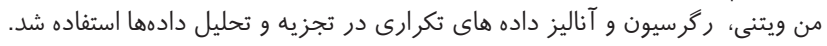

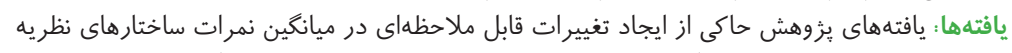

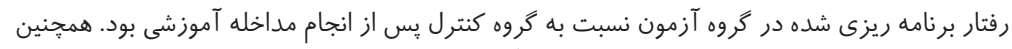

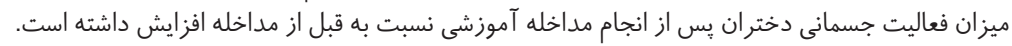

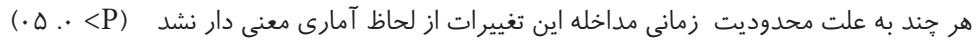

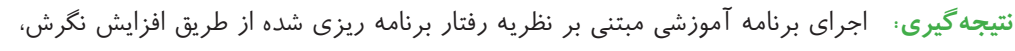

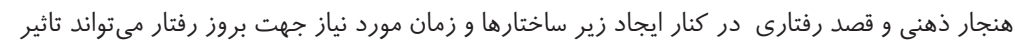

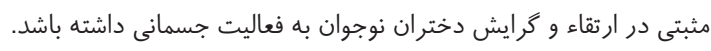

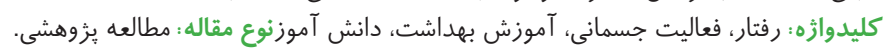

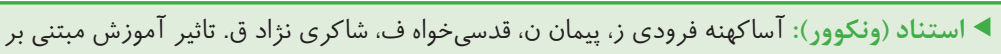

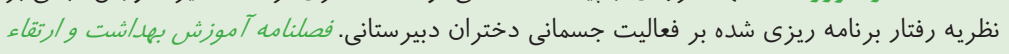

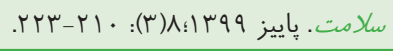

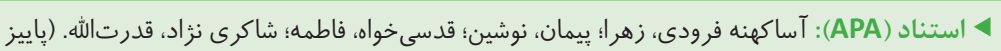

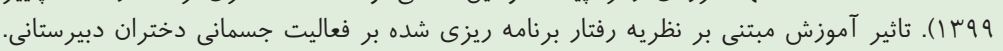

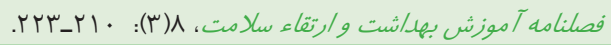


قبيل ورزش منظم به طور طبيعى در اين دوران آغاز شده و ادامه بيدا مى كند، اما متأسفانه ميزان فعاليت جسمانى به طور مداوم در اين دوران كاهش مى يابد( •(). در دو دهه كذشته فعاليت جسمانى در

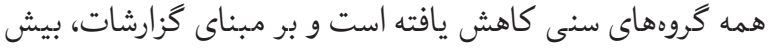
از •9 درصد از جمعيت نوجوانان جهان فعاليت جسمانى كافى كانى

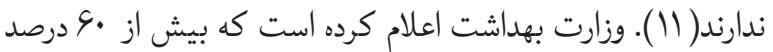
از زنان ايرانى تحرك خاصى ندارند. در تهران حدود هاّ درصد از زنان كروه سنى بf

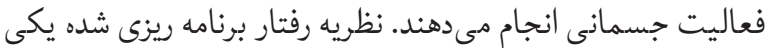

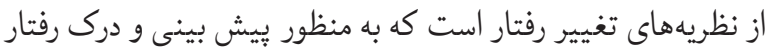

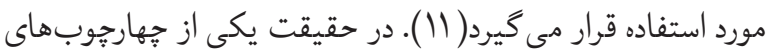
ادراكى موفق در زمينه رفتار فعاليت جسمانى زنان مىباشد(I (I). اين نظريه بيشنهاد مى كند كه نزديكترين تعيين كننده كليدى رفتار، قصد شخص براى انجام رفتار است. قصد، انكيزه واراده فرد براى تلاش جهت انجام رفتار مىباشد( Ir). قصد رفتارى به وسيله اساختار نكرش نسبت به اجراى يك رفتار (ارزشيابى مثبت يا

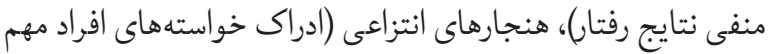
) و كنترل رفتارى درك شده (ادراك ميزان كنترل بر اجراى رفتار) تعيين مى گردد( (I|). شناسايى عوامل بيش بينى كننده قصد رفتارى براى ارتقاى قصد و رفتار فعاليت جسمانى امرى ضرورى است. زيرا تعيين اين عوامل موجب شناسايى ساختارهاى كليدى در طراحى مداخلات مؤثر آموزشى مى شودد. مطالعات مختلفى نشان دادهاند كه ارتباط واقعى و قوى بين هر يك از ساختارهاى تئورى رفتار برنامه

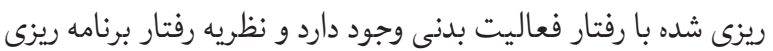
شده צY-MF درصد از واريانس قصد رفتارى را توضيح مىدهد (II) ). تحقيقات ورزشى نيز از توانايى بيش بينى كنندهى نظريه رفتار برنامه ريزى شده در رفتار ورزشى حمايت كردهاند. جون براى فهم تراني تعيين كنندهاى روانشناختى رفتار ورزشى شناسايى اعتقاداتى از فرد كه به طور قوى ترى با نكرش، هنجارهاى ذهنى و كنترل رفتارى درك شده ارتباط دارد، مهم است (If). بر اساس نتايج برخى بررسى هاريار
به هركونه حركت بدن كه در اثر انقباض و انبساط عضلات اسكلتى ايجاد شده و نيازمند صرف انرزى باشد، فعاليت جسمانى كفته مىشود ( ). فعاليت جسمانى سلامت و عملكرد استخوان را بهبود بخشيده و يك تعيين كننده اساسى براى مصرف و در نتيجه تعادل انرزى و كنترل وزن مىباشد(Y). ورزش و فعاليت جسمانى به عنوان يك رفتار بهداشتى مهم براى بيشكيرى از ابتلا به بيمارى و مركى برى و مير مطرح بوده و ارتباط مثبتى با ارتقاى سطح سلامت جسمى و ورئي

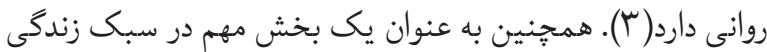
سالم جهت جلوگيرى از بروز بيماريهاى مزمن و حاقى در نظر كرفته

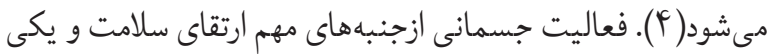

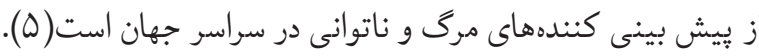
تحقيقات علمى بسيارى ثابت كرداند كه حتى مقدار متوسط فعاليت بدنى، خطر مرگ و مير ناشى از بيمارى هاى مزمن قلبى و ديابت را كاهش مىدهد و اثر حفاظتى زيادى در مقابل ديابت نوع دوم،

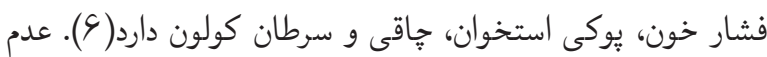
فعاليت جسمانى و ورزش منظم جهارمين عامل خطر عمده مرى

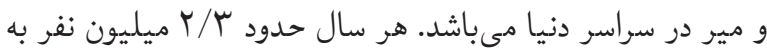
دليل نداشتن فعاليت بدنى جان خود را از دست مى دهند(V). عدم فعاليت جسمانى با بيش از يك ميليون مرگ زودرس مرتبط بوده و به عنوان يكى از مهمترين عوامل مرتبط با بار بيمارىها شناخته مىشود(^). تخمين زده مىشود كه فعاليت بدنى ناكافى مسئول

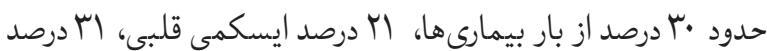

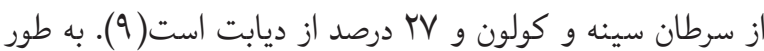

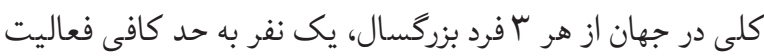

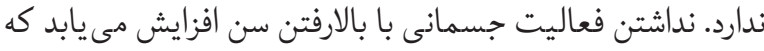

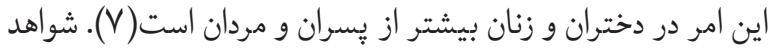
حاكى از كاهش فعاليت جسمانى منظم در آواخر دوره نوجوانى و اوايل جوانى هستند و اين كاهش يكى از معضلات بهداشت عمومى در اكثر كشورهاى جهان مى باشد. نوجوانى و جوانى دوره انتقال از كودكى به بزركسالى است و بسيارى از عادات زندگى از 
$\mathbf{n}=\frac{\left(z_{1-\alpha / 2}+z_{1-\beta}\right)^{2}\left(\delta_{1}^{2}+\delta_{2}^{2}\right)}{\left(\mu_{1}-\mu_{2}\right)^{2}}$

$\mathbf{n}=\frac{(1.96+0.84)^{2}\left(2.56^{2}+2.86^{2}\right)}{(1-.9-12.9)^{2}}=34$ جهت جمع آورى دادهها از برسشنامه باجى و همكاران ( (1)كه قبلا

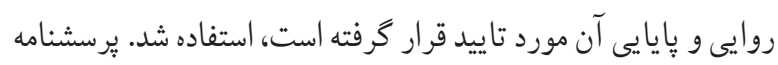

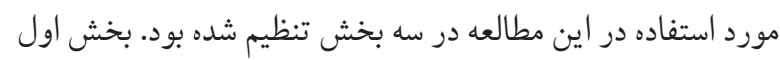

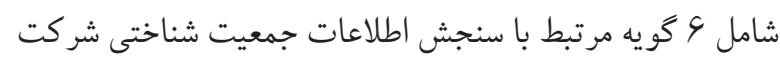

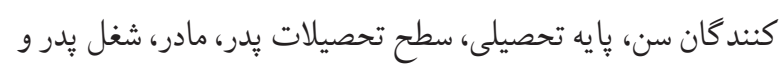

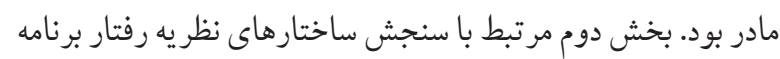

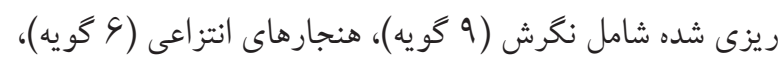

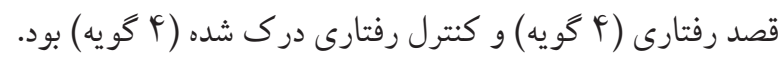

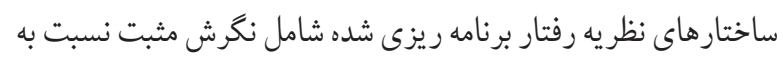

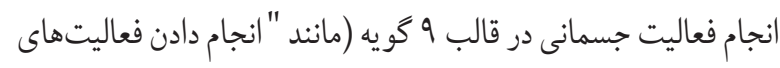

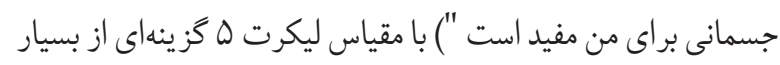

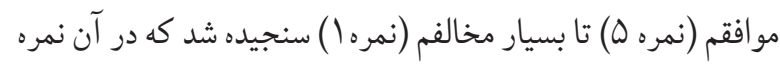
بالاتر نشان دهنده نكرش مثبت نسبت به انجام فعاليتهاى جسمانى مهانى

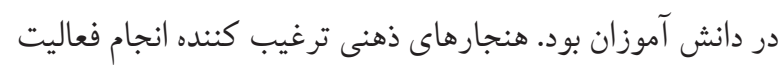

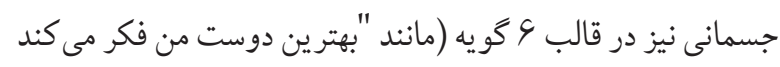

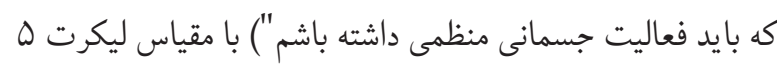

اعتقادات مرتبط با فعاليت فيزيكى، محيط اجتماعى و فيزيكى از

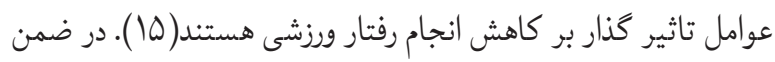

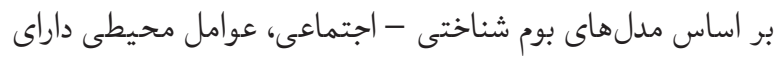

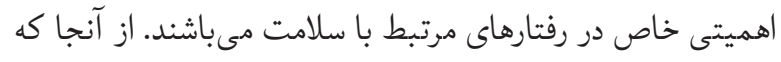

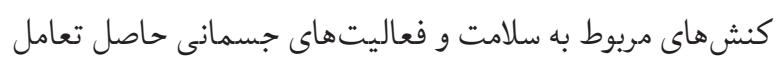
بين فرد و محيط مىباشد، محيط فيزيكى مى تواند فراهم كننده

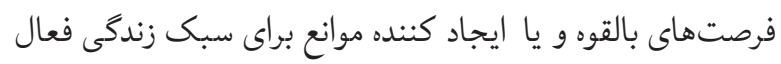

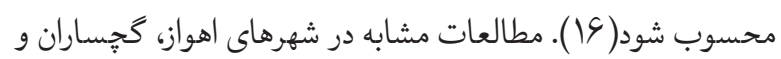

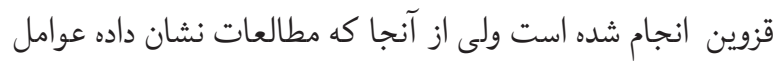

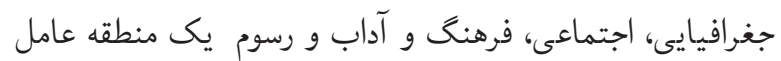

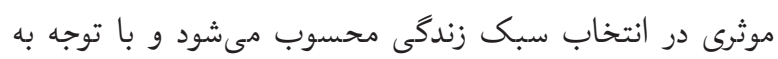

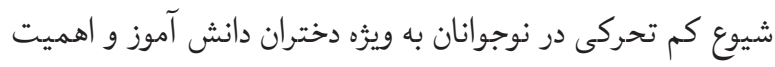

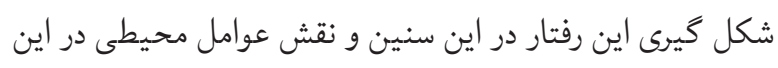
امر، يُوهش حاضر با هدف تعيين تاثير آموزش مبتنى بر نظريه رفتار برنامه ريزى شده بر فعاليت جسمانى دختران دبيرستانى شهر

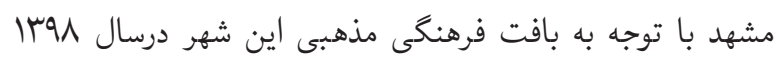
انجام شده است.

مو اد و روشها اين يُوهش يك مطالعه نيمه تجربى با گروه كنترل است كه بر

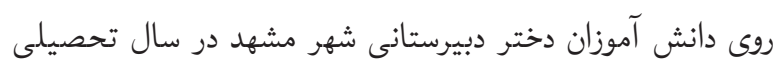

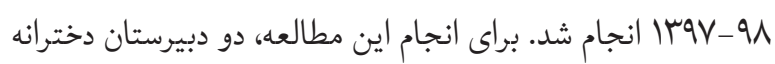

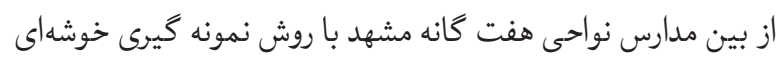

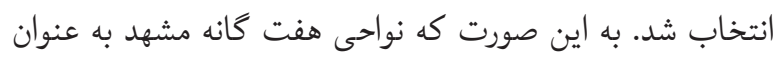

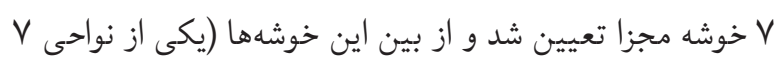

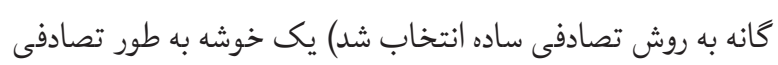
انتخاب شد. سيس از بين مدارسى كه در اين خوشه (ناحيه) قرار

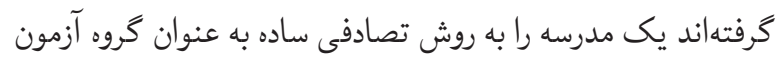
انتخاب كرديم و نزديكترين مدرسه به آن را جهت كروه كنترل انتخاب كرديم (تا نظر جغرافيايى و فرهنكى مشابهت داشته باشند).

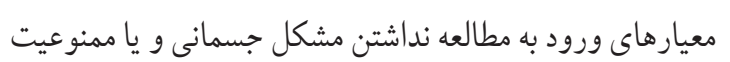


تا ا بود كه با توجه به نقطه برش جدول لاوشه، اعتبار ابزار مورد

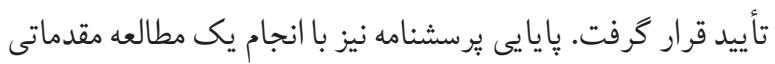

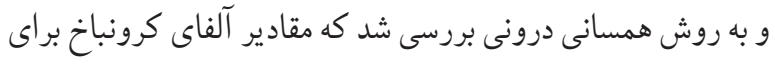

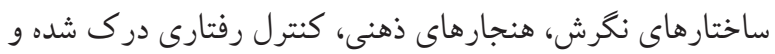

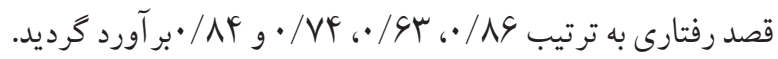

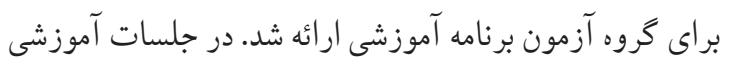

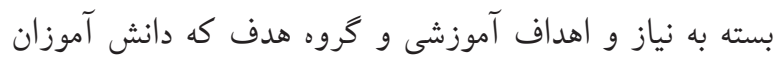

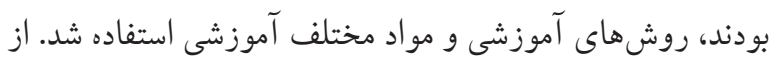

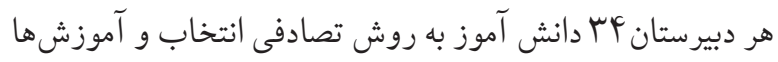

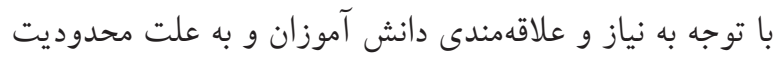

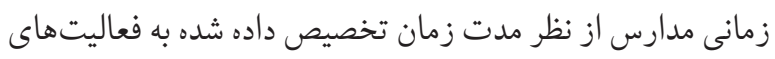

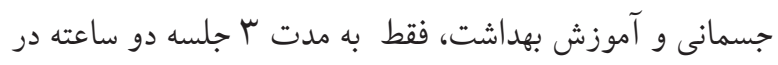

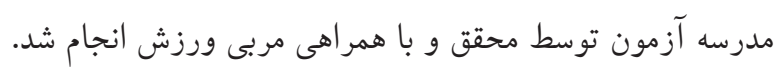

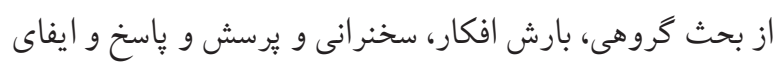

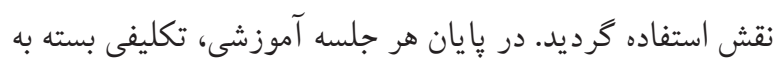

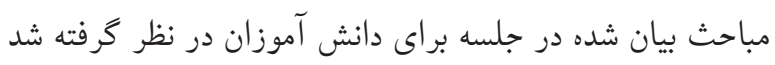

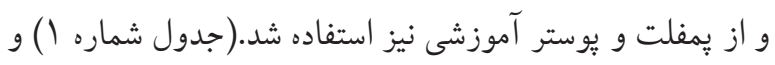

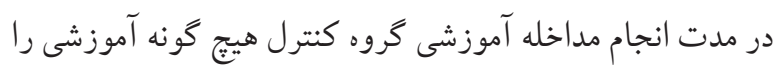

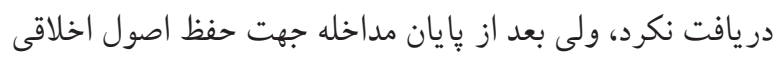
يُوهش گروه كنترل نيز آموزشهاى مربوط راد دريافت كردند.

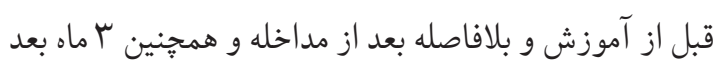
مجددا برسشنامه توسط همان واحدهاى يُزوهش تكميل و دادههاى

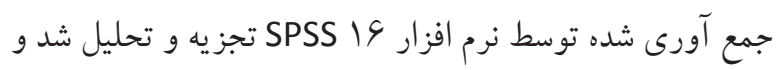
تاثير مداخله آموزشى مشخص كرديد.

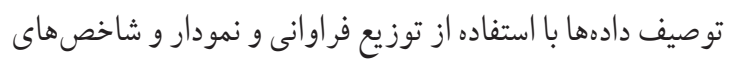
ميانكين يا ميانه، انحراف معيار يا دامنه ميان جاركى انجام شد.

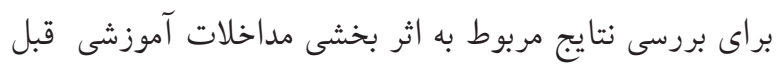

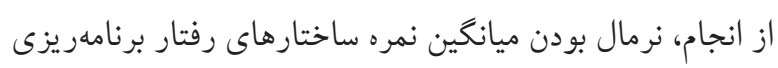

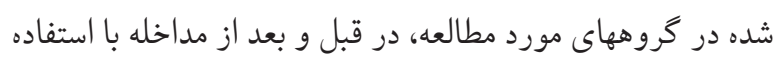

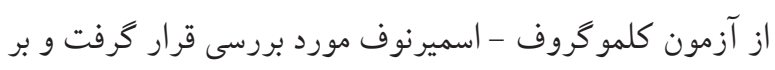
اساس نتايج آن از آمونهاى مرتبط با توجه به نرمال يا غير نرمال
كز ينهاى از بسيار مو افقم (نمره ه) تا بسيار مخالفم (نمره () اندازهيرى

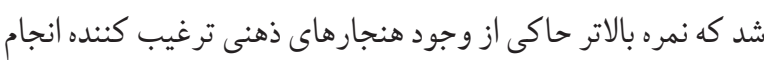

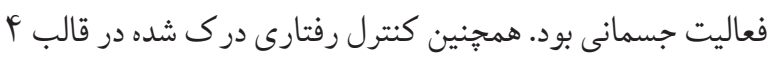

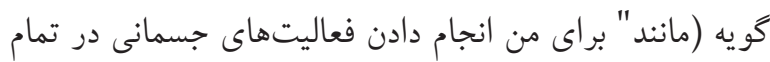

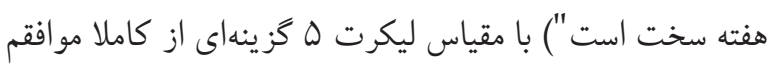

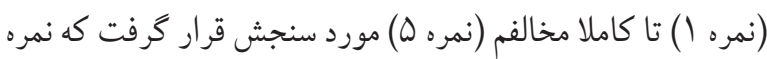

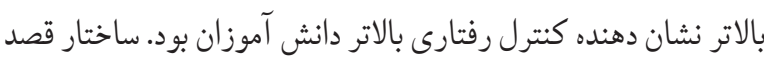

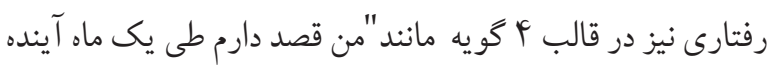

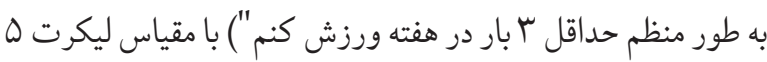

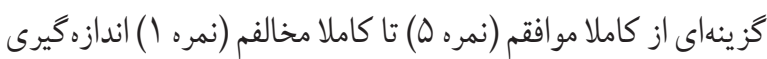
شد كه نمره بالاتر نشان دهنده وجود قصد قوى تر براى انجام فعاليت

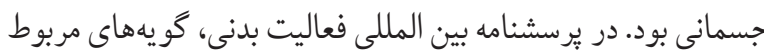

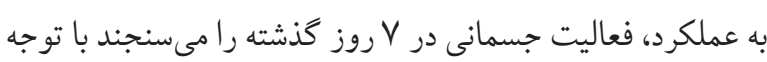

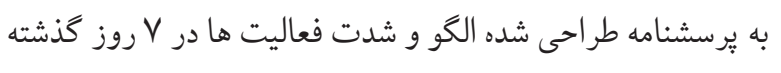

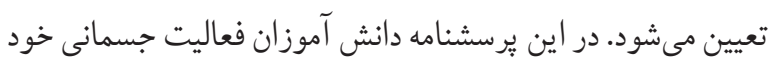

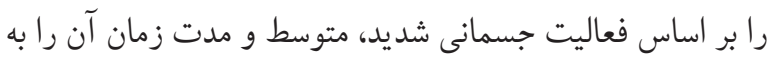

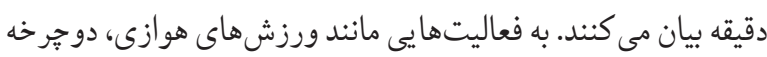

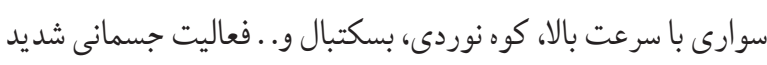

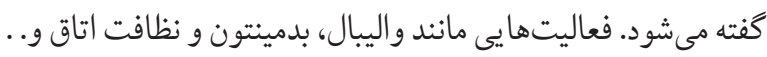
فعاليت جسمانى متوسط گفته مى شود. در اين برسشنامه مدت زمان فمان صرف شده جهت انجام فعاليت جسمانى در دانش آموزان كروه آزمون و كنترل قبل و بعد از مداخله آموزشى مورد مقايسه و ارزيابى قرار

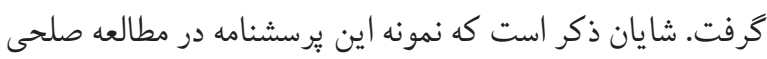

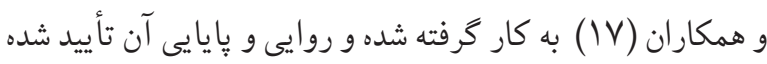
است. در اين مطالعه به منظور تعيين اعتبار علمى ابزار از روش اعتبار

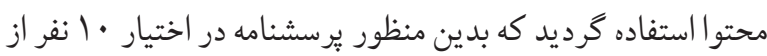
افر اد متخصص و صاحب نظر آموزش بهداشت و ارتقاى سلامت قرار

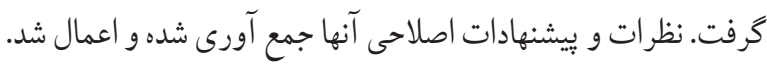
مقادير نسبت روايى محتواى (CVR: Content Validity Ratio)

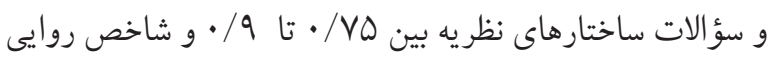

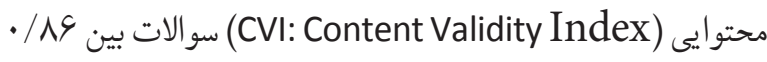




\begin{tabular}{|c|c|c|c|}
\hline زمان & آموزش بر اساس ساختارهاى نظريه رفتار برنامه ريزى & وسابل كمى آموزشى & تحوه اجرا \\
\hline rاعاع & 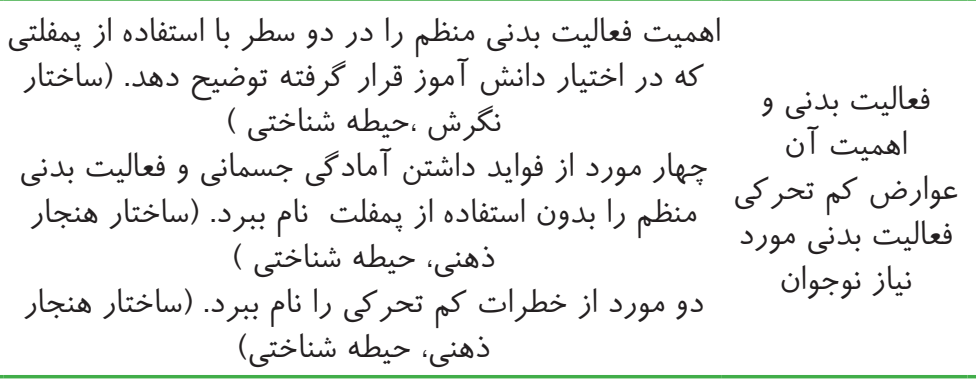 & مازيت برد، تخته & 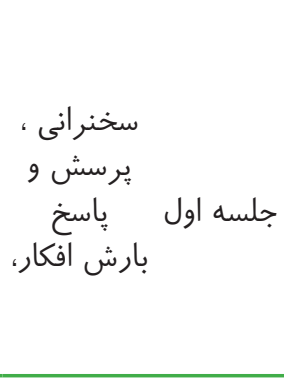 \\
\hline rاعاعت & 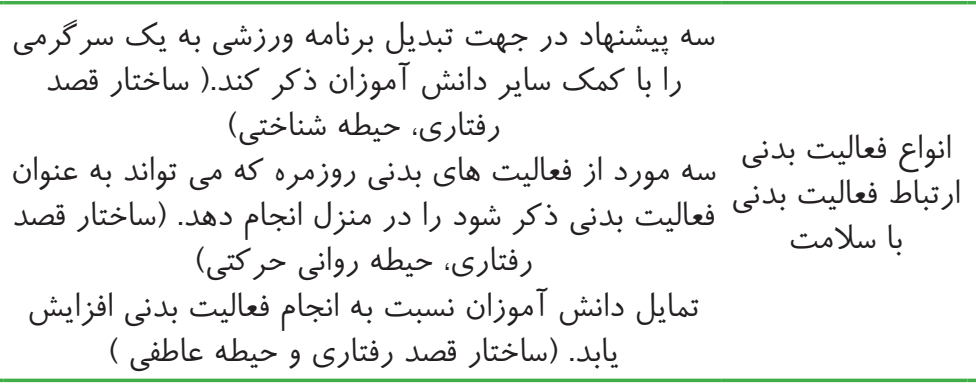 & مازيك، تخته & 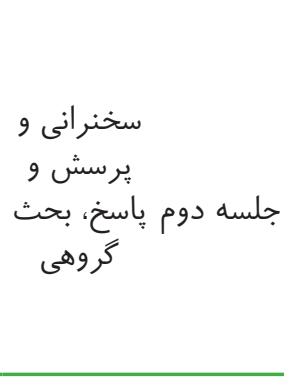 \\
\hline ل ساعت & 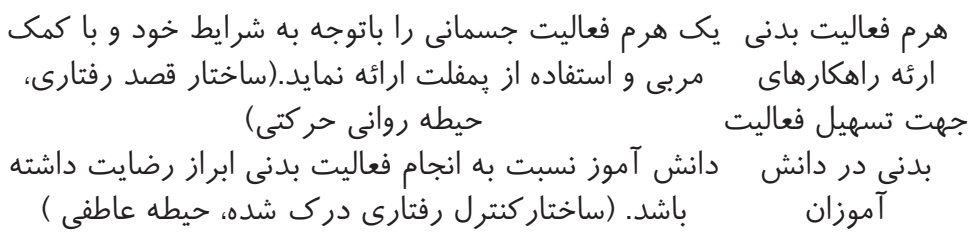 & مازيك، تخته & 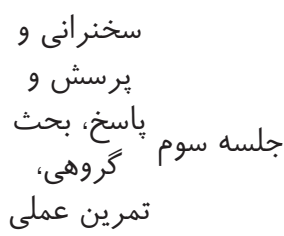 \\
\hline
\end{tabular}

متوسطه اول قرار داشتند در كروه آزمون و كنترل به ترتيب M/ON

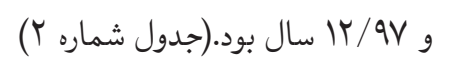

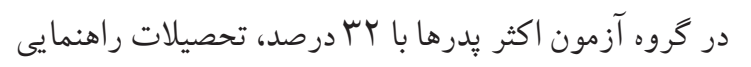

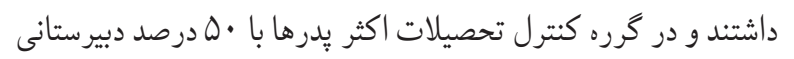

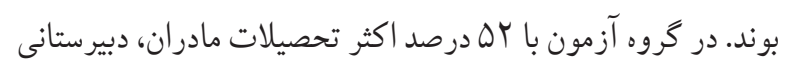

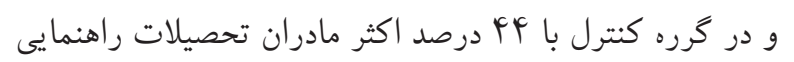

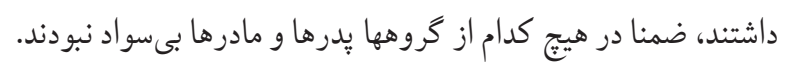

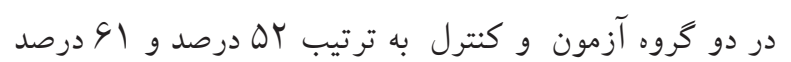

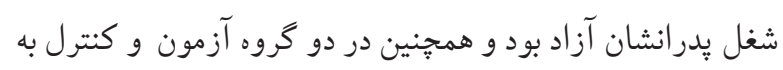

ترتيب اجو درصد و 9 د درصد از مادر دانش آموزان خانه دار بوند.

با توجه به نتايج آزمون متغيرهاى سن، تحصيلات يدر و تحصيلات

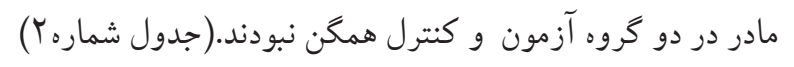

بودن داده ها از آزمون T-Test يا من -و يتنى استفاده شد. در تجزيه و تحليل دادهها جهت كنترل متغيرهاى مخدوشكر از آناليز دادههاى تكرارى و رگر سيون خطى نيز استفاده كرديد. اين طرح

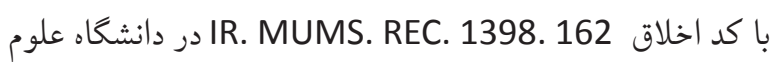
يزشكى مشهد به ثبت رسيد. ملاحظات اخلاقى كه درطى اين مطالعه مدنظر محققين قرار

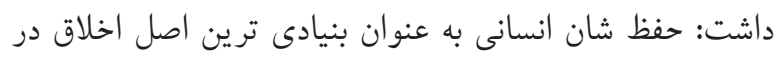

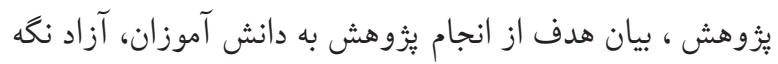
داشتن دانش آموزان جهت شركت در يُّوهش، محرمانه ماندن

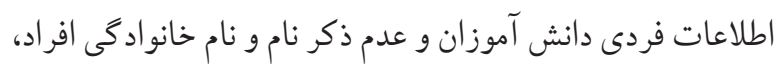
صداقت در جمع آورى و تحليل اطلاعات بود. نتايج ميانگين سنى دانش آموزان مورد مطالعه كه در مقطع تحصيلى 
جدول r: بررسى متغيرهاى جمعيت شناختى در دو كروه آزمون و كنترل

\begin{tabular}{|c|c|c|c|c|}
\hline نتيجه آزمون & كروه كنترل & كروه آزمون & \multicolumn{2}{|c|}{ متغير } \\
\hline P-value $=\cdot / \cdot r$ & $\mid r / 9 V(\cdot / \mid r)$ & $\mid r / \Delta \Lambda(\cdot / \cdot q)$ & & \\
\hline \multirow{5}{*}{$\mathrm{P}$-value $=\cdot / \mathrm{I}$} & $\cdot$ & . & بى سواد & \multirow{5}{*}{ "تحصيلات بدر } \\
\hline & $f(\Lambda / 11 \%)$ & $1 \cdot(\boldsymbol{F} / \tau q \%)$ & ابتدايى & \\
\hline & $\Lambda(\Delta / \digamma \mu \%)$ & $11(F / r r \%)$ & راهنمايى & \\
\hline & $\operatorname{lV}(\Delta \cdot \%)$ & $q(\Delta / r \varsigma \%)$ & دبير ستان & \\
\hline & $\Delta(V / \mid F \%)$ & $f(\Lambda / 11 \%)$ & دانشگاهى & \\
\hline \multirow{5}{*}{$\mathrm{P}$-value $=\cdot / \cdot 9$} & $\cdot$ & . & بى سواد & \multirow{5}{*}{ "**ق"تصيلات مادر } \\
\hline & $G(\varsigma / \mid \vee \%)$ & $V(\varsigma / \Upsilon \cdot \%)$ & ابتدايى & \\
\hline & $10(1 / F F \%)$ & $s(\varsigma / \mid \vee \%)$ & راهنمايى & \\
\hline & 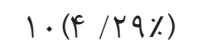 & $1 \wedge(9 / \Delta r \%)$ & دبير ستان & \\
\hline & $\mu(\Lambda / \Lambda \%)$ & $\mu(\Lambda / \Lambda \%)$ & دانشگاهى & \\
\hline \multirow{5}{*}{$\mathrm{P}$-value $=\cdot / \Delta \mathrm{V}$} & $\varsigma(\varsigma / \mid \vee \%)$ & $F(\wedge / 11 \%)$ & كارمند & \multirow{5}{*}{ } \\
\hline & $s(s / \mid \vee \%)$ & $q(\Delta / r s \%)$ & كارگر & \\
\hline & $r \mid(\Lambda / s \mid \%)$ & $\ln (9 / \Delta r \%)$ & آزاد & \\
\hline & . & . & بيكار & \\
\hline & $1(9 / r \%)$ & ヶ $(\Lambda / \wedge \%)$ & ساير & \\
\hline \multirow{4}{*}{$\mathrm{P}$-value $=\cdot|\varsigma|$} & $\operatorname{rr}(1 / 9 \uparrow \%)$ & $\mu \backslash(r / 91 \%)$ & خانه دار & \multirow{4}{*}{ } \\
\hline & . & $r(9 / \Delta \%)$ & كارمند & \\
\hline & $r(9 / 0 \%)$ & $1(9 / r \%)$ & آزاد & \\
\hline & . & . & ساير & \\
\hline
\end{tabular}

Tمن ويتنى *** كاى دو

نوع آزمون من ويتنى

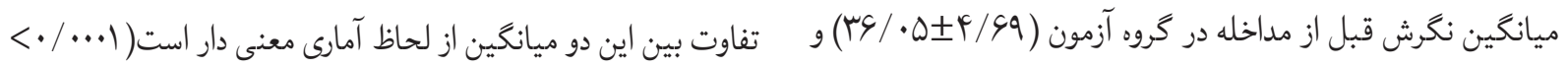

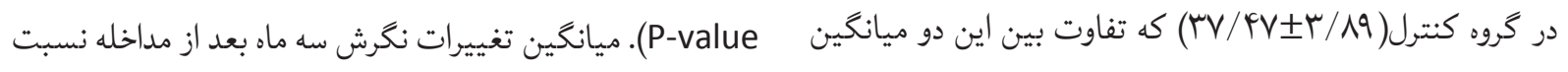

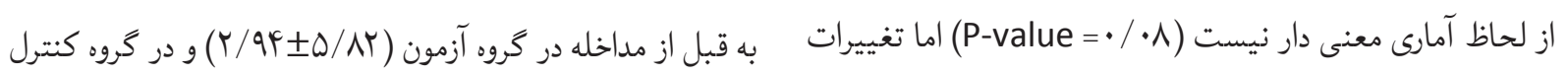
نكرش بلافاصله بعد از مداخله نسبت به قبل از مداخله در كروه (

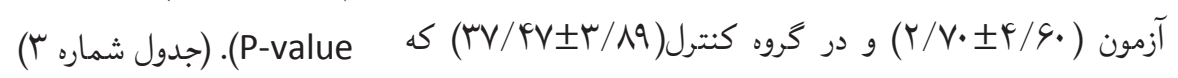


جدول ״ا: نتايج مقايسه ميانگين ها در ساختار هاى نظريه رفتارى برنامه ريزى شده در دو گروه كنترل و آزمون

\begin{tabular}{|c|c|c|c|c|}
\hline شده & ساختارهاى نظريه رفتار برنامه ريزى & 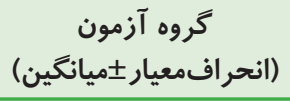 & 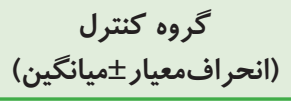 & نتيجه آزمون \\
\hline \multirow{3}{*}{$\begin{array}{l}\vec{v}_{2} \\
-3\end{array}$} & قبل مداخله & $r s / \cdot \Delta \pm(q / q q)$ & $r \vee / \mathscr{F} \vee \pm r / \wedge q($ & $\begin{array}{c}\mathrm{t}=-1 / \mathrm{Vf} \\
\mathrm{p}-\text { value }=\cdot / \cdot \wedge\end{array}$ \\
\hline & تغييرات بلافاصله بعد از مداخله نسبت به & $r / r \cdot) \pm r / G \cdot)$ & $-\cdot / \cdot r \pm(\cdot / l V)$ & $\begin{array}{c}\mathrm{Z}=\mathrm{F} / \Delta \cdot- \\
\mathrm{P}-\text { value }<\cdot / \cdots 1\end{array}$ \\
\hline & تغييرات سه ماه بعد از مداخله نسبت به & $r(9 r) \pm \Delta / \wedge r)$ & $\cdot(\cdot \Delta) \pm f(q 1)$ & $\begin{array}{c}\mathrm{Z}=1 / \mathrm{VH}^{\mu}- \\
\mathrm{P}-\text { value }=\cdot / \cdot \wedge\end{array}$ \\
\hline \multirow{3}{*}{ 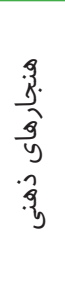 } & قبل مداخله & $|r / q| \pm(r / f q)$ & $\mid \Delta / \Delta \Lambda) \pm r / r \mid)$ & $\begin{array}{c}\mathrm{Z}=1 / 10_{-} \\
\mathrm{P}-\text { value }=\cdot / \mathrm{F}\end{array}$ \\
\hline & تغييرات بلافاصله بعد از مداخله نسبت به & $q / \mathcal{F} \mid \pm r / f q($ & $\Lambda / r \cdot) \pm 1 / \mathscr{F} \Delta($ & $\begin{array}{c}\mathrm{Z}=r / 1 \Lambda- \\
\text { P-value }=\cdot / \cdot r\end{array}$ \\
\hline & تغييرات سه ماه بعد از مداخله نسبت به & $\Lambda / \wedge \Lambda) \pm Y^{\prime} / \xi^{\mu}($ & $q(s V) \pm f / \cdot r)$ & $\begin{array}{c}\mathrm{T}=r / \cdot \wedge \\
\mathrm{P}-\text { value }=\cdot / \cdot r\end{array}$ \\
\hline \multirow{3}{*}{ 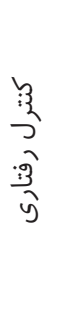 } & قبل مداخله & $|r /| 1 \pm r / \Delta \mid$ & $|q / \cdot \Delta \pm \mu /| v$ & $\begin{array}{c}\mathrm{Z}_{=}=/ \mathrm{V} q_{-} \\
\mathrm{P}-\text { value }=\cdot / \mathrm{Fr}\end{array}$ \\
\hline & تغييرات بلافاصله بعد از مداخله نسبت به & $\mid \digamma / \Delta \Lambda \pm(\mu / \Lambda \cdot($ & $\mid f / V \Psi) \pm|/| r)$ & $\begin{array}{c}\mathrm{Z}=\cdot / \Delta r- \\
\mathrm{P}-\text { value }=\cdot / \Delta 9\end{array}$ \\
\hline & تغييرات سه ماه بعد از مداخله نسبت به & $1 / V \cdot) \pm r /(V)$ & $\cdot(\mathcal{F} F) \pm r / \Lambda \Lambda)$ & $\begin{array}{c}\mathrm{Z}=1 / \cdot \Delta_{-} \\
\mathrm{P}-\text { value }=\cdot / \mathrm{q}^{-}\end{array}$ \\
\hline \multirow{3}{*}{$\begin{array}{l}3 \\
3 \\
\text { के } \\
\text { पे }\end{array}$} & ق ق قبل مداخله & $(r / 9 V) \pm r / \cdot \Delta)$ & $(0 / \cdot 1) \pm 1 / 94)$ & $\begin{array}{c}Z=r / \wedge r- \\
P \text {-value }=\cdot / \cdot \varphi\end{array}$ \\
\hline & تغييرات بلافاصله بعد از مداخله نسبت به & $\cdot(91) \pm r(\cdot \Delta)$ & $-\cdot|f| \pm|/ \varsigma|)$ & $\begin{array}{c}Z=1 / 99- \\
\text { P-value }=\cdot / \cdot r\end{array}$ \\
\hline & تغييرات سه ماه بعد از مداخله نسبت به مداخله & $1 / \Delta \Delta) \pm r / \wedge \mu)$ & $-\cdot(s r) \pm r / \lambda r)$ & $\begin{array}{c}\mathrm{Z}=r / \Delta Q_{-} \\
\mathrm{P}-\text { value }=\cdot / \cdot 1\end{array}$ \\
\hline \multirow{3}{*}{$\begin{array}{l}3 \\
3 \\
3 \\
3 \\
3: \\
3 \\
3 \\
3 \\
3 \\
3 \\
3 \\
3\end{array}$} & قبل مداخله & $q \mu / q \vee) \pm(\mid r / \Lambda 1)$ & $r V / \Delta r) \pm r q /(r)$ & $\begin{array}{c}\mathrm{Z}=r / 1 \wedge- \\
\mathrm{P}-\text { value }=\cdot / \cdot r\end{array}$ \\
\hline & تغييرات بلافاصله بعد از مداخله نسبت به & $(V / r \cdot) \pm \mid r V / V \Psi)$ & $r \wedge / \wedge r) \pm r \vee q / \varphi()$ & $\begin{array}{c}\mathrm{Z}_{=\cdot} / \mathrm{Hr}_{-} \\
\mathrm{P}-\text { value }=\cdot / \mathrm{VF}\end{array}$ \\
\hline & تغييرات سه ماه بعد از مداخله نسبت به مداخله & $(Y V / r \cdot) \pm r r V / r \Lambda)$ & $r S / G() \pm \Delta F / V r)$ & $\begin{array}{c}\mathrm{Z}=r / 9 r- \\
\mathrm{P}-\text { value }=\cdot / \cdot r\end{array}$ \\
\hline \multirow{3}{*}{$\begin{array}{c}3 \\
3 \\
3 \\
: 3 \\
3: \\
3 \\
3 \\
3 \\
3 \\
3 \\
3 \\
3\end{array}$} & قبل مداخله & $\vee \wedge / \Delta r) \pm \wedge \Delta / ৭ \Lambda)$ & $\Delta F / Y G) \pm \wedge \Delta / G \cdot)$ & $\begin{array}{c}\mathrm{Z}=1 / \mathrm{r} \cdot- \\
\mathrm{P}-\text { value }=\cdot / 10\end{array}$ \\
\hline & تغييرات بلافاصله بعد از مداخله نسبت به & $r r / \vee q) \pm|V| / \wedge \Lambda)$ & $G(G \mid) \pm Y \Delta / Y \mid)$ & $\begin{array}{c}\mathrm{Z}=\cdot / r 1- \\
\mathrm{P}-\text { value }=\cdot / \wedge r\end{array}$ \\
\hline & تغييرات سه ماه بعد از مداخله نسبت به & $(r q / \Delta \Delta) \pm r(N / q \mu)$ & $f / F \mid \pm(k F / q 1)$ & $\begin{array}{c}\mathrm{Z}=1 / \Delta \mathrm{V}- \\
\mathrm{P}-\text { value }=\cdot / 11\end{array}$ \\
\hline
\end{tabular}


ادامه جدول س: نتايج مقايسه ميانگين ها در ساختار هاى نظريه رفتارى برنامه ريزى شده در دو گروه كنترل و آزمون

\begin{tabular}{|c|c|c|c|c|}
\hline \multirow{3}{*}{$\begin{array}{l}3: \\
\text { 3: } \\
\text { के }\end{array}$} & قبل مداخله & $\mid F V / \cdot \Delta \pm F r \mu / F G$ & $\wedge \Delta / \wedge \Lambda) \pm \Lambda \mid /(r)$ & $\begin{array}{c}\mathrm{Z}=1 \\
\mathrm{P} \text {-value }=\cdot / \cdots 1\end{array}$ \\
\hline & تغييرات بلافاصله بعد از مداخله نسبت به & $r \Delta /(f) \pm \Delta \cdot \Delta / \mu \vee)$ & $\Psi r / T \Delta) \pm(F r / \Delta r)$ & $\begin{array}{c}\mathrm{Z}=1 / \varsigma 9_{-} \\
\mathrm{P}-\text { value }=\cdot / \cdot \wedge\end{array}$ \\
\hline & تغييرات سه ماه بعد از مداخله نسبت به & $(r r / V q) \pm \Delta r r / V \cdot)$ & $\cdot(F F) \pm(\cdot \Delta / r \Lambda)$ & $\begin{array}{c}\mathrm{Z}=r / 19- \\
\mathrm{P}-\text { value }=\cdot / \cdots 1\end{array}$ \\
\hline \multirow{3}{*}{.3} & قبل مداخله & $r \wedge \Delta / \wedge \Lambda) \pm(r \wedge / r q)$ & 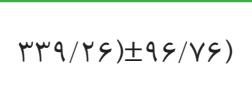 & $\begin{array}{c}\mathrm{Z}=1 / 9 \mathrm{~V}- \\
\mathrm{P}-\text { value }=\cdot / \cdot 9\end{array}$ \\
\hline & تغييرات بلافاصله بعد از مداخله نسبت به & $-\Delta / \Delta \Lambda) \pm(9 \varsigma / 9 \vee)$ & 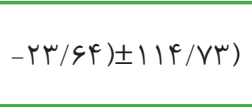 & $\begin{array}{c}\mathrm{Z}_{=} \cdot / \mathrm{V}^{\mu}- \\
\mathrm{P}-\mathrm{value}=\cdot / \uparrow \varsigma\end{array}$ \\
\hline & تغييرات سه ماه بعد از مداخله نسبت به & $(/ \Delta \Delta) \pm r / \wedge \mu)$ & $-0) \pm(91 / 41)$ & $\begin{array}{c}\mathrm{t}=\cdot|\Delta|- \\
\mathrm{P}-\text { value }=\cdot|\varsigma|\end{array}$ \\
\hline
\end{tabular}

ميانكين قصد رفتارى قبل از مداخله در گروه آزمون ( اين دو ميانگين از لحاظ آمارى معنى دار نيست (P-value =• (

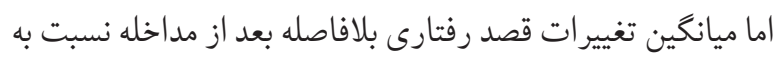

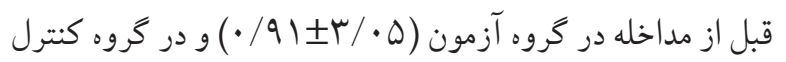

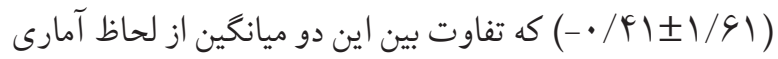

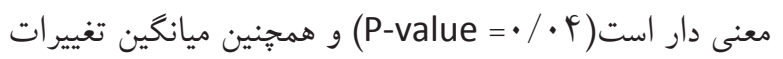
قصد رفتارى سه ماه بعد از مداخله نسبت به قبل از مداخله در كروه

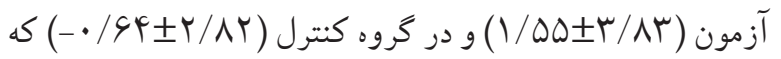

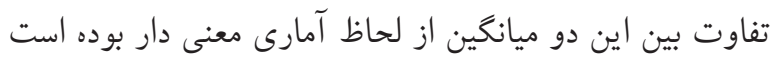

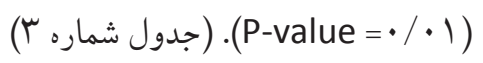

ميانگين هنجارهاى ذهنى قبل از مداخله در گروه آزمون

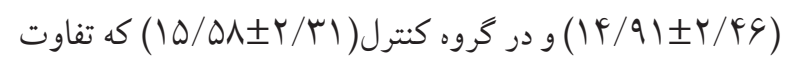

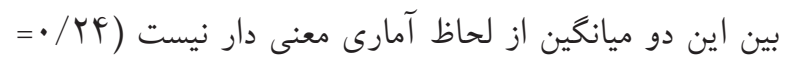
(P-value

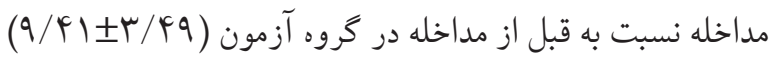

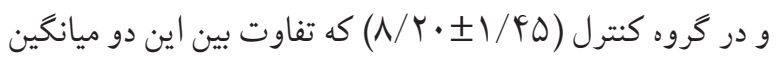

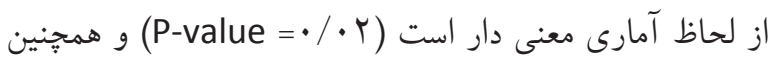

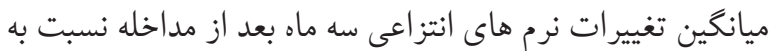

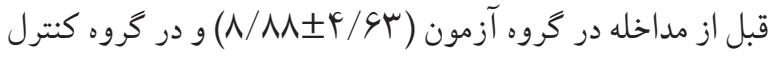

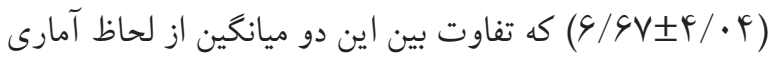

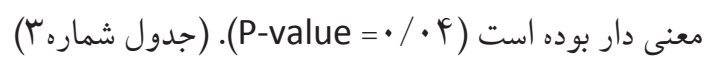

جدول ⿷ا: تغييرات ساختارهاى نظريه رفتار برنامه ريزى شده با كنترل متغير هاى مخدوش كننده

\begin{tabular}{|c|c|c|c|c|}
\hline & كروه & ضريب رگرسيون & خطاى استاندارد & نتايج آزمون \\
\hline \multirow{2}{*}{ نخرش بلافاصله بعد از مداخله } & 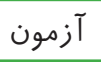 & $1 / 99$ &.$/ 9$ & p-value $=\cdot / \cdot r$ \\
\hline & 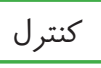 & Reference & - & - \\
\hline \multirow{2}{*}{ نخرش سه ماه بعد از مداخله } & آز آزمون & $r / 90$ & $1 / Y 1$ & $\mathrm{p}$-value $=\cdot / \cdot \mathrm{l}$ \\
\hline & كنترل & Reference & - & - \\
\hline
\end{tabular}




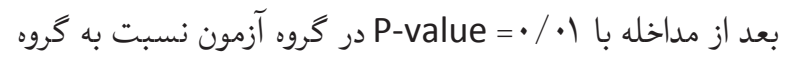

كنترل Y/ Y افزايش داشته است.(جدول شماره Y)

هنجارهاى ذهنى سه ماه بعد از مداخله با كنترل متغيرهاى

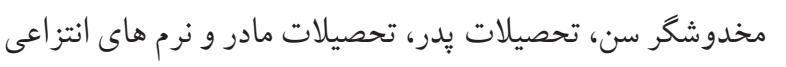

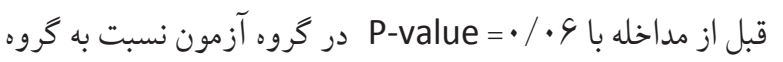

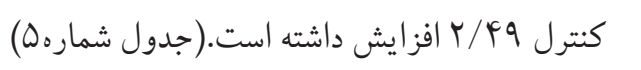

با توجه به اين كه متغيرهاى سن، تحصيلات پدر و تحصيلات مادر

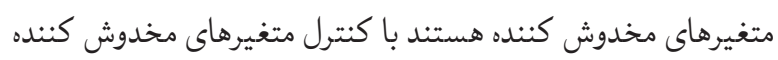
نتايج زير حاصل شده است. با كنترل متغيرهاى مخدوشكر سن، تحصيلات پدر، تحصيلات مادر و نكرش قبل از مداخله، نكرش

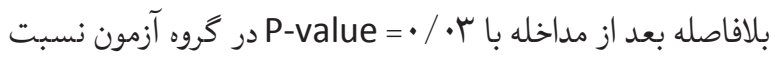

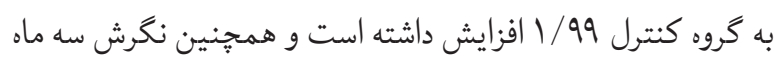

جدول ه: تغييرات ساختارهاى نظريه رفتار برنامه ريزى شده با كنترل متغيرهاى مخدوش كننده

\begin{tabular}{|c|c|c|c|c|}
\hline & كروه & ضريب ركرسيون & خطاى استاندارد & نتايج آزمون \\
\hline \multirow{2}{*}{ هنجارهاى ذهنى بلافاصله بعد از } & آزمون & $\cdot / \mathbb{F}$ & $\cdot / V^{c}$ & $p-$ value $=\cdot / \Delta \Lambda$ \\
\hline & كنترل & Reference & - & - \\
\hline \multirow{2}{*}{ هنجارهاى ذهنى سه ماه بعد از } & آزمون & $r / r q$ & $1 / r \& 9$ & $\mathrm{p}$-value $=. / .4$ \\
\hline & كنترل & Reference & - & - \\
\hline
\end{tabular}

نوع آزمون: آناليز داده هاى تكرارى جدول و: تغييرات ساختارهاى نظريه رفتار برنامه ريزى شده با كنترل متغير هاى مخدوش كنده

\begin{tabular}{|c|c|c|c|c|}
\hline & كروه & ضريب رگر سيون & خطاى استاندارد & نتايج آزمون \\
\hline \multirow{2}{*}{ كنترل رفتارى بلافاصله بعد از } & آزمون & $-1 / 91$ & $1 / r 4$ & $\mathrm{p}$-value $=\cdot / 1 \mu$ \\
\hline & كنترل & Reference & - & - \\
\hline \multirow{2}{*}{ نترل رفتارى سه ماه بعد از مداخله } & آزمون & $\cdot / r q$ &.$/ 4 G$ & $\mathrm{p}-$ value $=\cdot / \mathrm{v}$ \\
\hline & كنترل & Reference & - & - \\
\hline
\end{tabular}

نوع آزمون: آناليز داده هاى تكرارى

قصد رفتارى بلافاصله بعد از مداخله و قصد رفتارى سه ماه كنترل رفتارى بلافاصله بعد از مداخله و كنترل رفتارى سه

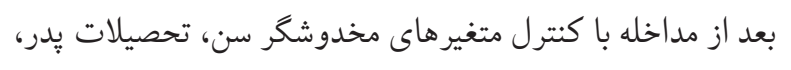
ماه بعد از مداخله با كنترل متغيرهاى مخدوشكر سن، تحصيلات

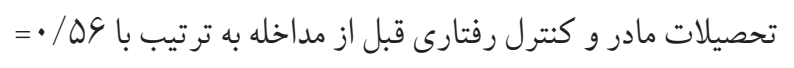

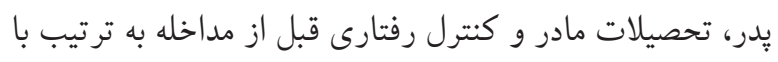
در گروه آزمون نسبت به خروه كنترل P-value =• /VA, P-value

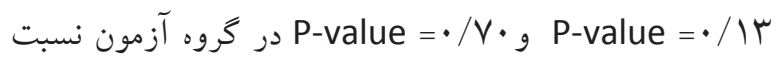
از لحاظ آمارى معنى دار نبود.(جدول شماره و (V) به گروه كنترل از لحاظ آمارى معنى دار نبود. (جدول شماره ( جدول V: تغييرات ساختارهاى نظريه رفتار برنامه ريزى شده با كنترل متغيرهاى مخدوش كننده

\begin{tabular}{|c|c|c|c|c|}
\hline & كروه & ضريب رگرسيون & خطاى استاندارد & نتايج آزمون \\
\hline \multirow{2}{*}{ قصد رفتارى بلافاصله بعد از } & آآمون & $-\cdot / \mu r$ & .109 & $\mathrm{p}-$ value $=\cdot / \Delta s$ \\
\hline & كنترل & Reference & - & - \\
\hline \multirow{2}{*}{ قصد رفتارى سه ماه بعد از مداخله } & آزمون & $\cdot / 19$ & $\cdot / \mathrm{V} \Lambda$ & $\mathrm{p}$-value $=\cdot / r \mathrm{v}$ \\
\hline & كنترل & Reference & - & - \\
\hline
\end{tabular}


همراه در دانشكاه غنا براساس تئورى رفتار برنامه ريزى "انجام شد

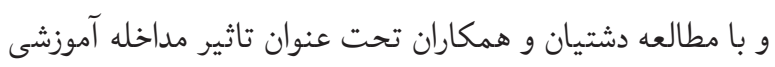

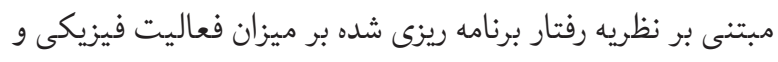

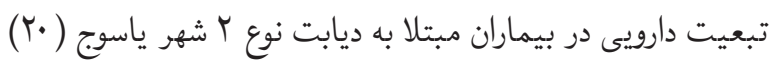

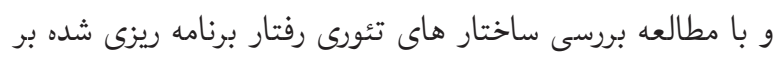

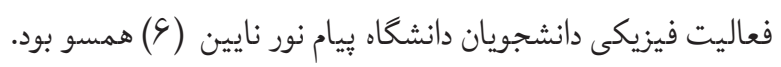

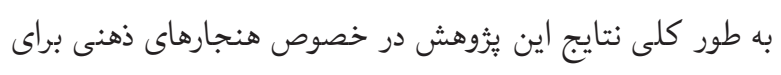

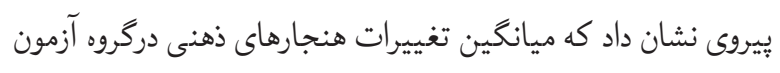

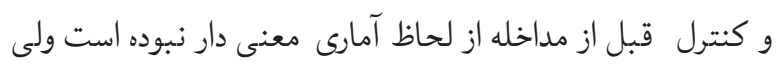

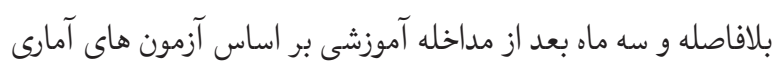

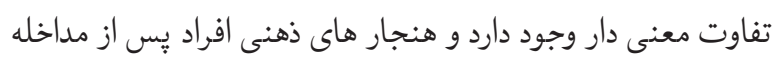

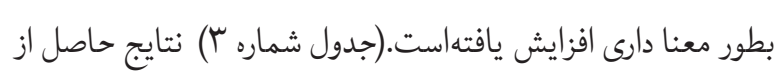

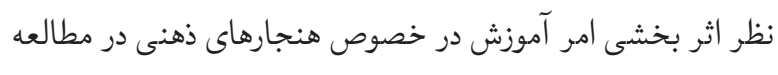

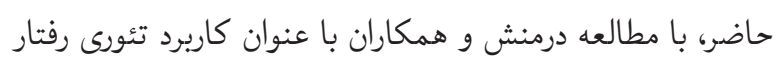

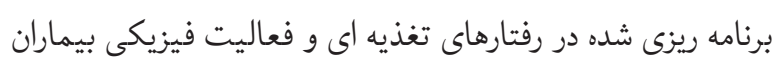

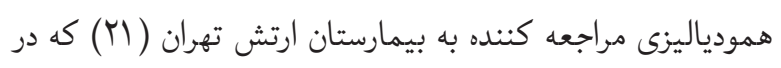

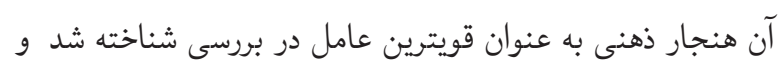

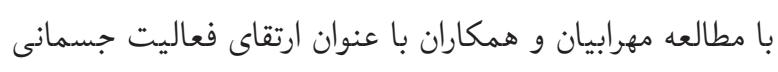
بر اساس تئورى رفتار برنامه ريزى شده در كنترل فشارخون بيماران

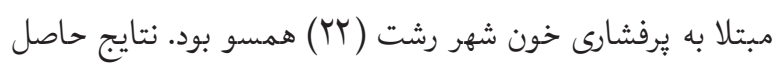

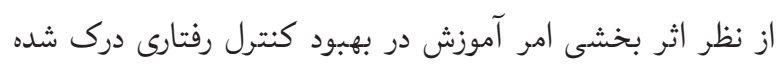

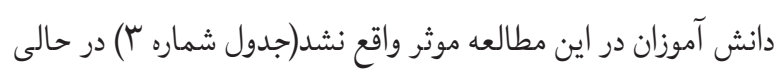
كه در مطالعه يكانى نزاد وهمكاران با عنوان كاربرد تئورى رفتار

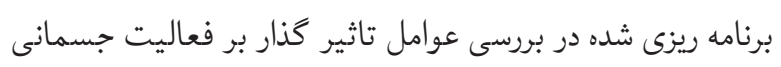

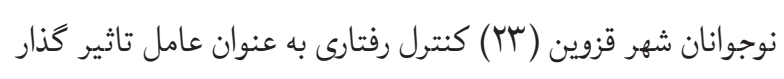

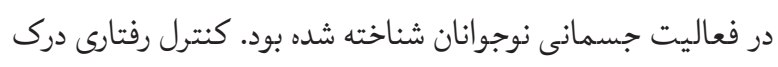
شده ، درجه درك فرد از سهولت يا دشوارى اتخاذ يك رفتار مى بـ باشد.

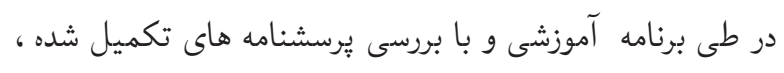

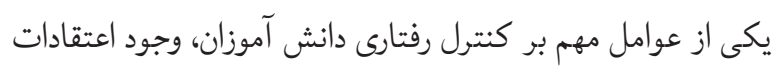

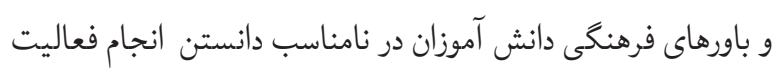

بحث و نتيجها كيرى

rr.

بر اساس يافته هاى بُوهشي، مداخله اموزشى باعث ارتقاء فعاليت

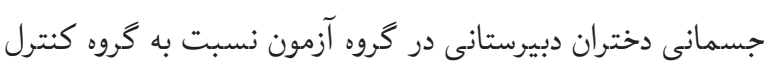

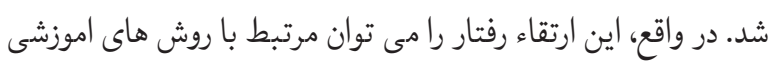

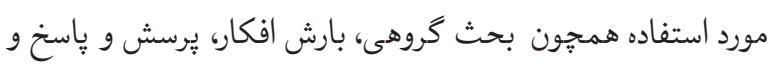

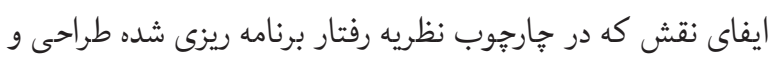

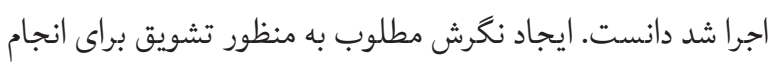

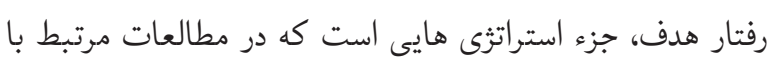

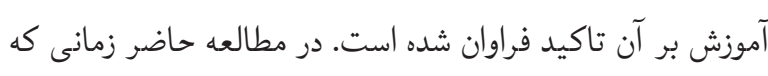

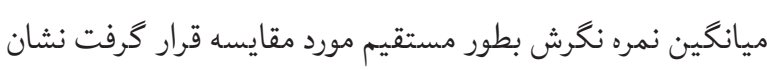

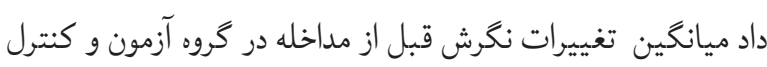

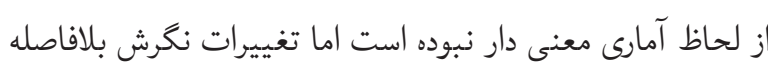

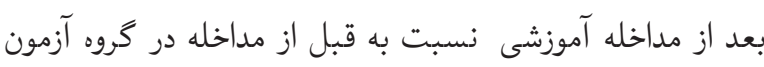

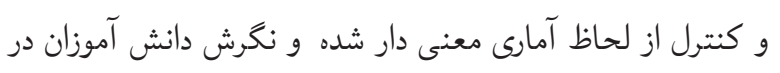

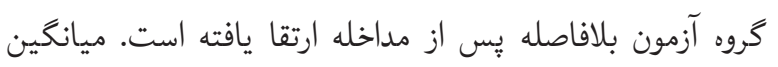

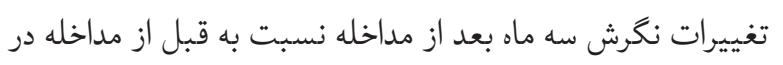

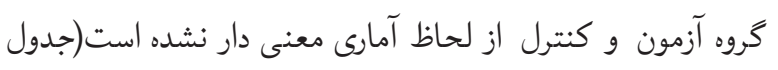

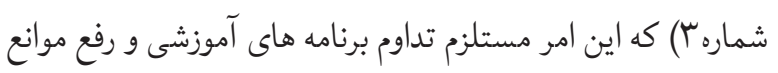

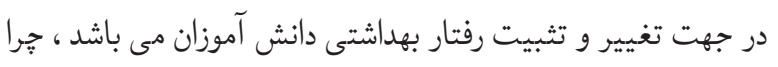

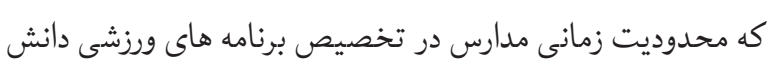

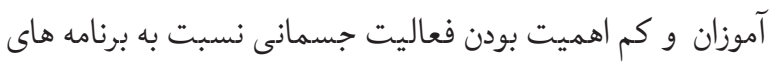

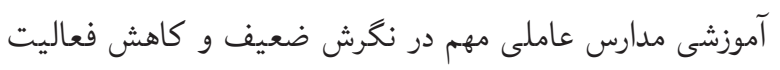

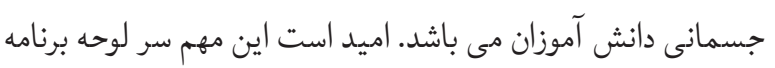

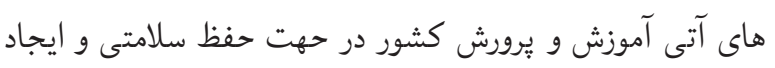
رفتار جسمانى مناسب در دانش آموزان قرار كيرد. نتايج حاصل

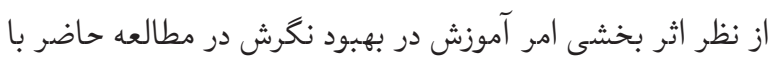

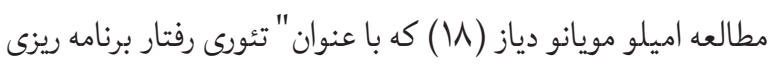

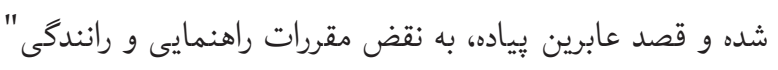

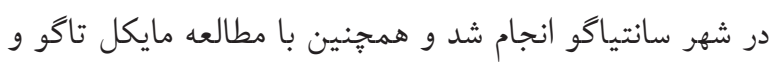

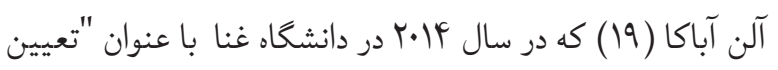

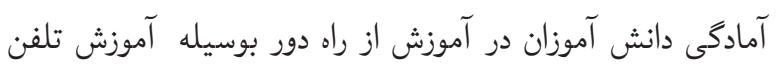


متغيرهاى سن، تحصيلات يدر و تحصيلات مادر متغيرهاى مخدوش كننده هستند با كنترل اين متغيرهاى مخدوش كننده نمرات نكرش، دهري،

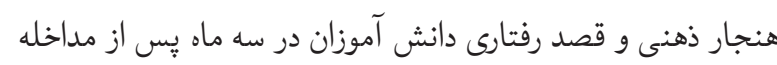

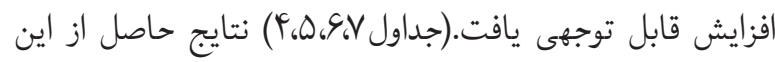

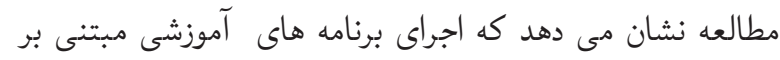

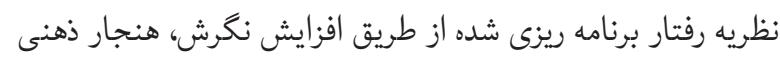

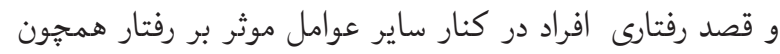
سياست كذارى ها و ايجاد زير ساخت هاى لازم جهت ايجاد رفتار بهداشتى مطلوب مى تواند تاثير مثبتى در ارتقا ء و كرايش دختران نوجوان به فعاليت جسمانى داشته باشد و استفاده صحيح از الكوها و نظريه هاى تغيير رفتار در اجراى برنامه هاى آموزشى مى تواند نتايج مفيدى در بیى داشته باشد.

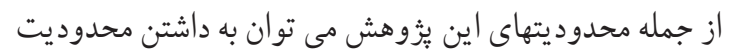

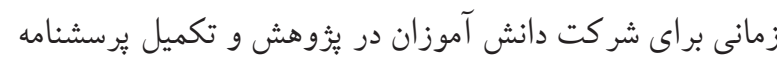

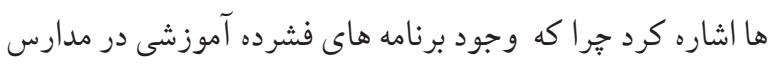

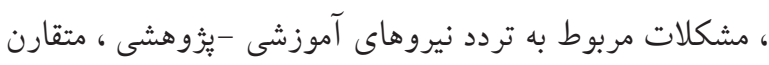

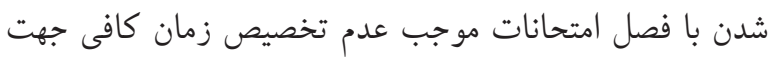
فعاليت جسمانى، و بهداشتى دانست در حالى كه ارتقا و تثبيت

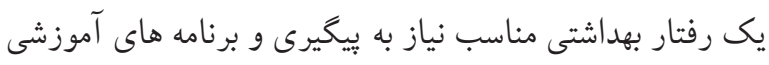

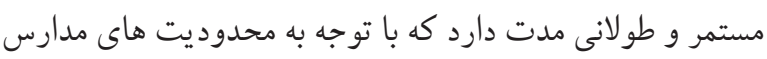

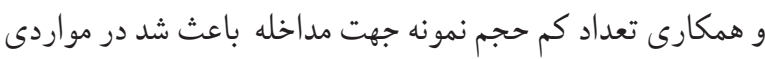
نتايج آزمون ها آمارى معنى دار نشود ولى خوشبختانه تغييرات انجام شده در رفتار دانش آموزان ملموس و قابل توجه بود د ، علاوه داه

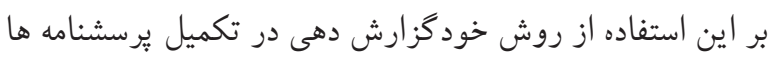

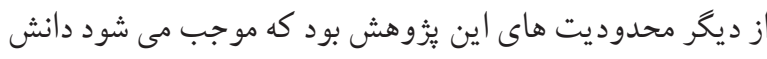

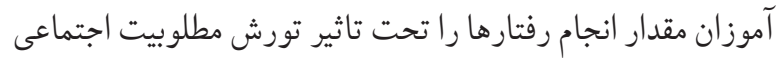

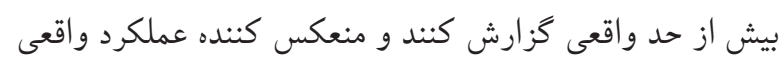

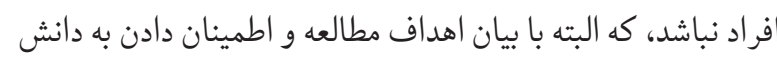

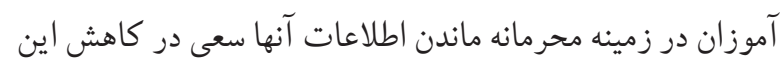
محدوديت گرديد.

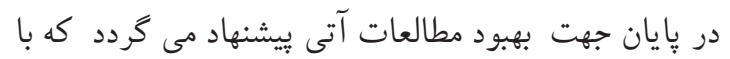

جسمانى بانوان در فضاها و معابر شهرى دانست و در اين ميان نبود امكانات و فضاهاى ورزشى مناسب بانوان باعث سختى درى افراد از انجام رفتار فعاليت جسمانى شده است، كه مى توان با احداث فضاهاى ورزشى كم هزينه و در دسترس بانوان كامى موثر در ارتقا

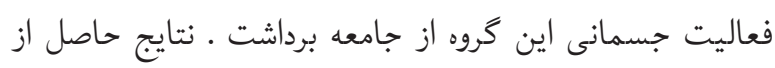

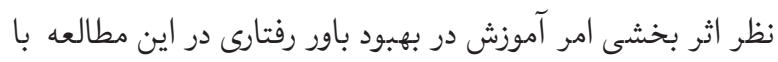

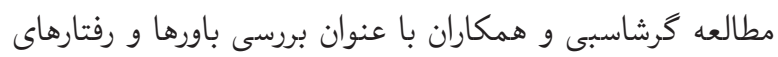

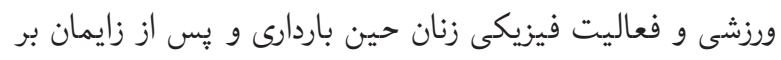

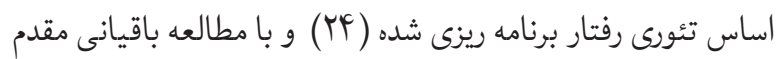

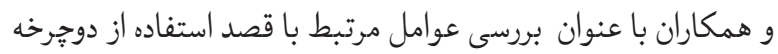

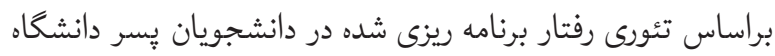

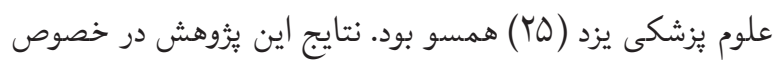

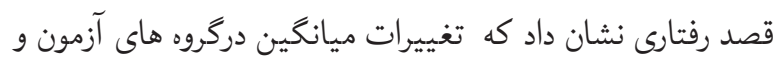

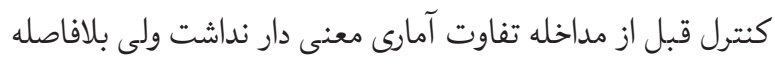

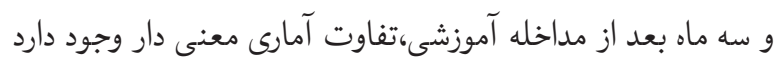

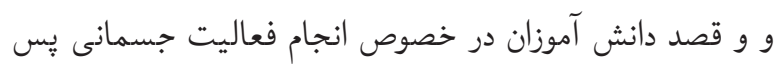

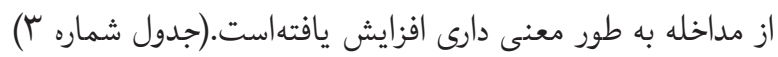
نتايج مطالعه باجى و همكاران با عنوان عوامل مرتبط با قصد انجام

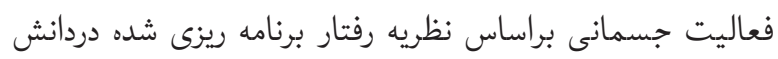

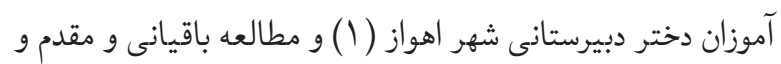
همكاران با عنوان بررسى عوامل مرتبط با قصد استفاده از دوجرخه براساس تئورى رفتار برنامه ريزى شده در دانشجويان يسر دانشعاه

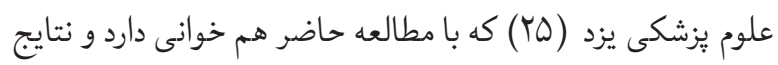

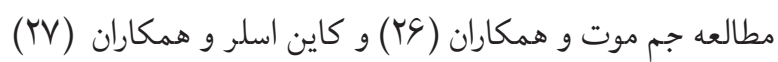

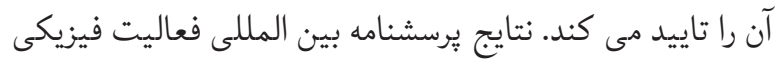

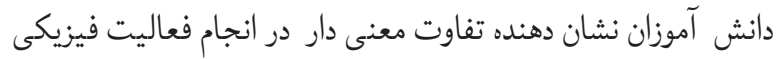

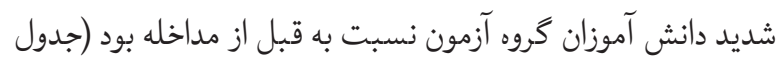

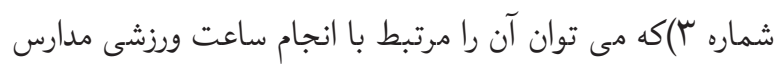

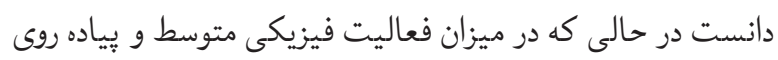

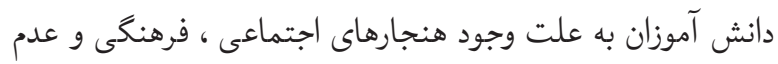

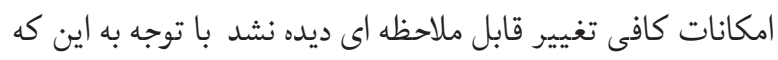


باشد. نويسندكان اين مقاله بر خود لازم مى دانند تا بدينوسيله از

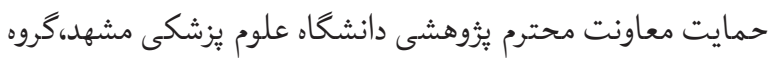

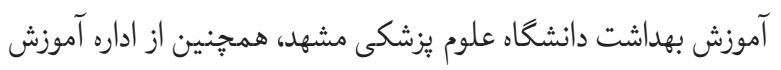

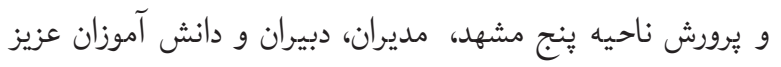

دبيرستان هاى دخترانه و رابط بهداشتى مدارس اين ناحيه سركار

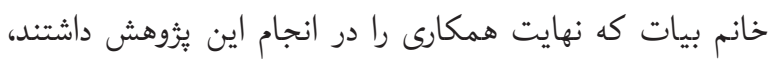

$$
\text { صميمانه تشكر و قدردانى نمايند. }
$$

\section{References}

1. Baji Z, Shakerinejad G, Tehrani M, Hajinajaf S, Jarvandi F. Factors Related to Intention to Perform Physical Activity Based on the Theory of Planned Behavior among High School Female Students in Ahvaz. Journal of Education and Community Health. 2017;4(3):52-8.

2. Fakhrzadeh H, Djalalinia S, Mirarefin M, Arefirad T, Asayesh $\mathrm{H}$, Safiri $\mathrm{S}$, et al. Prevalence of physical inactivity in Iran: a systematic review. Journal of cardiovascular and thoracic research. 2016;8(3):92.

3. GERAVANDI A, GHOFRANIPOUR F, REZAEI M, LAGHAEI $Z$, SEPAHI S. Effect of health education on promotion of physical activity in housewives who refer to health centers of Kermanshah. 2014.

4. Khodamoradi F, Mozafarsaadati H, Nabavi S, Hosseini S. The survey level of physical activity and stage of change among high school. J North Khorasan Univ Med Sci. 2014;6(2):289-95.

5. Musavian AS, Pasha A, Rahebi S-M, Roushan ZA, Ghanbari A. Health promoting behaviors among adolescents: $A$ cross-sectional study. Nursing and midwifery studies. 2014;3(1).

6. Saber F, Shanazi H, Sharifrad G. The survey of theory of planned behavior constructs regarding girl student's physical activity in Naein payame Noor University in 2012. J Health Syst Res. 2013;9(9):1014-21.

7. Gholamnia-shirvani Z, Ghofranipour F, Gharakhanlo R, Kazemnezhad A. Improving and Maintaining Physical Activity and Anthropometric Indices in females from Tehran\&58; Application of the Theory of Planned Behavior. Journal of education and Community Health. 2016;2(4):13-24.

8. Pratt M, Perez LG, Goenka S, Brownson RC, Bauman A, Sarmiento OL, et al. Can population levels of physical activity be increased? Global evidence and experience. Progress in cardiovascular diseases. 2015;57(4):356-67.

$$
\begin{aligned}
& \text { تعداد بيشتر از حجم نمونه مطالعات آتى انجام يذيرد و علاوه بر } \\
& \text { اين در برنامه هاى آموزشى ، مدت زمان بيشترى جهت استقرار و } \\
& \text { تثيبت يك رفتار بهداشتى مناسب در نظر گرفته شود. همجنين جهت } \\
& \text { مقايسه عوامل موثر بر رفتار در دوجنس بهتر است مطالعات همزمان } \\
& \text { و با شرايط اجتماعى ، فرهنكى يكسان در دو جنس انجام شود. } \\
& \text { تشكر و قدردانى } \\
& \text { اين مقاله مصوب دانشخاه علوم يزشكى مشهد با كد ..9V19 مى }
\end{aligned}
$$

9. SUN MC, Kawthur BA. Leisure-time physical activity among university students in Mauritius. American Journal of Health Research. 2013;1(1):1-8.

10. Salahshuri A, Sharifirad G, Hassanzadeh A, Mostafavi F. Physical activity patterns and its influencing factors among high school students of Izeh city: Application of some constructs of health belief model. Journal of education and health promotion. 2014;3.

11. Aghamolaei T, Farshidi H, Safari Moradabadi A, Dadipoor S. Effect of interventions based on the theory of planned behavior on promoting physical activity: a systematic review. Journal of Preventive Medicine. 2017;3(4):15-1.

12. Shirvani ZG, Ghofranipour F, Gharakhanlou R, Kazemnejad A. Determinants of physical activity based on the theory of planned behavior in Iranian Military Staff's Wives: a path analysis. Global journal of health science. 2015;7(3):230.

13. Conner M, Sandberg T, Norman P. Using action planning to promote exercise behavior. Annals of Behavioral Medicine. 2010;40(1):65-76.

14. Downs DS, Hausenblas HA. Elicitation studies and the theory of planned behavior: a systematic review of exercise beliefs. Psychology of sport and exercise. 2005;6(1):1-31.

15. Levy SS, Cardinal BJ. Factors associated with transitional shifts in college students' physical activity behavior. Research Quarterly for Exercise and Sport. 2006;77(4):47685.

16. Mohamadian H, Eftekhar H, Rahimi A, Mohamad HT, Shojaiezade D, Montazeri A. Predicting health-related quality of life by using a health promotion model among Iranian adolescent girls: A structural equation modeling approach. Nursing \& Health Sciences. 2011;13(2):141-8.

17. solhi $m$, ZINATMOTLAGH F, KARIMZADE SK, TAGHDISI $\mathrm{MH}$, jalilian f. Designing and implementing educational program to promote physical activity among students: An application of the theory of planned behavior. 2012. 
18. Diaz EM. Theory of planned behavior and pedestrians' intentions to violate traffic regulations. Transportation Research Part F: Traffic Psychology and Behaviour. 2002;5(3):169-75.

19. Tagoe MA, Abakah E. Determining Distance Education Students' Readiness for Mobile Learning at University of Ghana Using the Theory of Planned Behavior. International Journal of Education and Development using Information and Communication Technology. 2014;10(1):91-106.

20. Dashtianmm m E-Ah, Karimzadeh-Shirazi k,, Shahmoradi $\mathrm{m}$ Ak, Piraee e. The Effect of Educational Intervention, Based on the Theory of Planned Behavior, on Medication Adherence and Physical Activity in Patients with Type 2 Diabetes Mellitus. Journal of Health System Research. 2017;14(1):40-7.

21. v. ddbhS, $v$ T. The application of the theory of planned behavior in nutritional behaviors and physical activity of hemodialysis patients referring to army hospitals. pagohan. 2016;15(2):55-63.

22. $f$ mfr. The effect of physical activity promotion on the theory of planned behavior in controlling hypertension in patients with hypertension referring to rural health centers in Rasht in 2014. Quarterly Journal of Health Education and Health Promotion of Iran. 2018;6(1):0-.
23. a ynma. Investigating the Factors Affecting Physical Activity in Adolescents in Qazvin: An Application of Theory of Planned Behavior. Journal of North Khorasan University of Medical Sciences. 2013;4(3).

24. s gamh. Study of sport beliefs and behaviors and physical activity of women during pregnancy and postpartum based on the theory of planned behavior. Bimonthly Scientific Journal Shahed University - The twenty-first year of issue No 115. 2013.

25. $\mathrm{m}$ bmmqa. Investigating Factors Related to Bicycle Intention Based on Theory of Planned Behavior in Male Students of Yazd University of Medical Sciences. Scientific research journal Yazd School of Public Health Thirteenth year Number: Fourth October and November 2014.

26. Jemmott JB, Jemmott LS, Fong GT. Efficacy of a theorybased abstinence-only intervention over 24 months: a randomized controlled trial with young adolescents. Archives of pediatrics \& adolescent medicine. 2010;164(2):152-9.

27. Kinsler JJ, Wong MD, Sayles JN, Davis C, Cunningham WE. The effect of perceived stigma from a health care provider on access to care among a low-income HIV-positive population. AIDS patient care and STDs. 2007;21(8):58492. 